NBER WORKING PAPER SERIES

WHAT MAKES US GOVERNMENT BONDS SAFE ASSETS?

\author{
Zhiguo He \\ Arvind Krishnamurthy \\ Konstantin Milbradt \\ Working Paper 22017 \\ http://www.nber.org/papers/w22017 \\ NATIONAL BUREAU OF ECONOMIC RESEARCH \\ 1050 Massachusetts Avenue \\ Cambridge, MA 02138 \\ February 2016
}

We thank Manuel Amador and Jonathan Wallen for comments, and Pierre-Olivier Gourinchas for his discussion of our work at the 2015 NBER Summer Institute. The views expressed herein are those of the authors and do not necessarily reflect the views of the National Bureau of Economic Research.

At least one co-author has disclosed a financial relationship of potential relevance for this research. Further information is available online at http://www.nber.org/papers/w22017.ack

NBER working papers are circulated for discussion and comment purposes. They have not been peerreviewed or been subject to the review by the NBER Board of Directors that accompanies official NBER publications.

(C) 2016 by Zhiguo He, Arvind Krishnamurthy, and Konstantin Milbradt. All rights reserved. Short sections of text, not to exceed two paragraphs, may be quoted without explicit permission provided that full credit, including $\odot$ notice, is given to the source. 
What Makes US Government Bonds Safe Assets?

Zhiguo He, Arvind Krishnamurthy, and Konstantin Milbradt

NBER Working Paper No. 22017

February 2016

JEL No. E0,F0,F3,G0,G11

\section{ABSTRACT}

US government bonds are widely considered to be the world's safe store of value. US government bonds are a large fraction of safe asset portfolios, such as the porfolios of many central banks. The world demand for safe assets leads to low yields on US Treasury bonds. During periods of economic turmoil, such as the events of 2008, these yields fall even further. Moreover, despite the fact that US government debt has risen substantially relative to US GDP over the last decade, US government bond yields have not risen. What makes US government bonds "safe assets"? Our answer in short is that safe asset investors have nowhere else to go but invest in US government bonds.

Zhiguo He

University of Chicago

Booth School of Business

5807 S. Woodlawn Avenue

Chicago, IL 60637

and NBER

zhiguo.he@chicagobooth.edu
Konstantin Milbradt

Kellogg School of Management

Northwestern University

2001 Sheridan Rd \#401

Evanston, IL 60208

and NBER

milbradt@northwestern.edu

Arvind Krishnamurthy

Stanford Graduate School of Business

Stanford University

655 Knight Way

Stanford, CA 94305

and NBER

akris@stanford.edu 


\title{
What makes US government bonds safe assets?*
}

\author{
Zhiguo He ${ }^{\dagger}$ Arvind Krishnamurthy ${ }^{\ddagger}$ and Konstantin Milbradt ${ }^{\S}$
}

January 28, 2016

US government bonds are widely considered to be the world's safe store of value. US government bonds are a large fraction of safe asset portfolios, such as the porfolios of many central banks. The world demand for safe assets leads to low yields on US Treasury bonds. During periods of economic turmoil, such as the events of 2008, these yields fall even further. Moreover, despite the fact that US government debt has risen substantially relative to US GDP over the last decade, US government bond yields have not risen. What makes US government bonds "safe assets"? Our answer in short is that safe asset investors have nowhere else to go but invest in US government bonds.

Figure 1 provides some motivating evidence. The figure plots the interest rate on 3month Treasury Bills (3m-Tbill, in solid black), along with the Federal Funds target rate (dashed line) and the rate on the 3-month Federal Funds Overnight Index Swap (3m-OIS in grey line). The latter rate reflects the expected overnight Federal Funds rate over the next 3 months so that its maturity is comparable to the 3 -month Treasury Bill rate. The figure shows that the Treasury bill rate is below the other money market rates. Most striking is that at times of worsening economic fundamentals - March 2008 with the demise of Bear Stearns, and October 2008 with the demise of Lehman Brothers - the yield on Treasury bills falls substantially relative to the other money market rates (Federal Funds in the figure, but also relative to non-bank money market rates such as high grade non-financial commercial paper which is not in the figure). In these episodes, US government debt should be expected to rise substantially due to an impending recession and the possibility of large scale transfer payments from the government. And yet, the yields on US government debt fall relative to the yields of other debt. These observations beg the question of why US government debt is a safe asset, especially given a high US debt-to-income ratio. More broadly, these observations are interesting in the context of the growing literature on safe assets (see Caballero et al. [2008], Caballero and Krishnamurthy [2009], and Krishnamurthy and Vissing-Jorgensen [2012]), and raise the question of what makes an asset a "safe asset."

*We thank Manuel Amador and Jonathan Wallen for comments, and Pierre-Olivier Gourinchas for his discussion of our work at the 2015 NBER Summer Institute.

†University of Chicago, Booth School of Business, and NBER. Address: 5807 South Woodlawn Ave, Chicago, IL 60637; Phone: 773-834-3769; Email: zhiguo.he@chicagobooth.edu.

${ }^{\ddagger}$ Stanford University, Graduate School of Business, and NBER. Address: 655 Knight Way Stanford, CA 94305; Phone: 650-723-1985; Email: a-krishnamurthy@stanford.edu.

$\S$ Northwestern University, Kellogg School of Management, and NBER. Address: 2001 Sheridan Road, Evanston, IL 60208; Phone: 847-491-8618; Email: milbradt@northwestern.edu. 


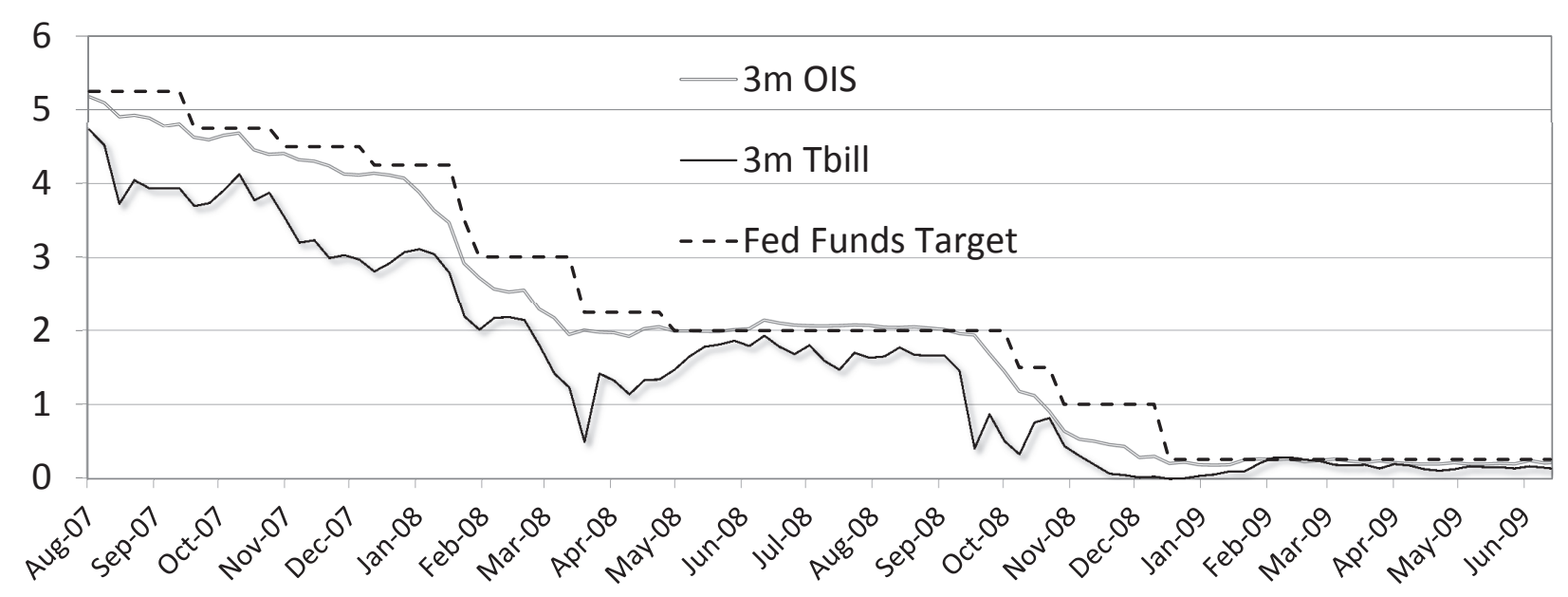

Figure 1: Safe asset yields, August 2007 to June 2009

\section{Model}

There are two countries $(i=\mathrm{A}, \mathrm{B})$ that have sovereign debt outstanding at date $t$ of $b_{t}^{i}$. This debt matures at date $t$ and must be rolled over or defaulted on. Our model determines conditions under which the time $t$ debt of $b_{t}^{i}$ is safe debt. Each country can issue new debt of $b_{t+1}^{i}$ to rollover the existing debt. We assume that the new debt has to pay with certainty at date $t+1$. The maximum amount of such debt that a country can credibly issue is $B_{t+1}^{i}$, which is exogenous to our model. Without loss of generality we call country A the "large country" (i.e. the US) and assume that $B_{t+1}^{A}>B_{t+1}^{B}$. Note that this is a statement that the maximum amount (float) of country A debt is larger than that of country B debt. It is not a statement regarding the countries' debt/GDP ratios. In fact, to make our point most clearly, let us suppose that the ratio of $\frac{B_{t+1}^{i}}{G D P_{t+1}^{i}}$ is the same across these countries so that fundamental repayment ability of the two countries are the same. We will show that it is the larger absolute debt capacity of country A that makes its time $t$ debt of $b_{t}^{i}$ to be the safe asset, rather than the typical variables that affect debt sustainability.

There is a continuum of risk-neutral investors at date $t$. In total the investors have $f$ units of goods to invest. They must invest their funds in either the debt of country A or B. Importantly, there is no other asset, or storage technology, in which to invest. We can think of these investors as foreign central banks who collectively have $f$ funds that they must invest in the safe sovereign debts of other countries, and they face a portfolio choice of buying country A and/or B debt.

Given the past debt of $b_{t}^{i}$ that is due at date $t$, country- $i$ faces a rollover problem. Suppose that country- $i$ issues $b_{t+1}^{i}$ units of bonds at price $p_{t}^{i}$ that will be endogenously determined in equilibrium. For simplicity, we assume that each country issues as much safe debt as it can, so that $b_{t+1}^{i}=B_{t+1}^{i}{ }^{1}$ Then country- $i$ 's proceeds from the bond issue are $p_{t}^{i} B_{t+1}^{i}$. The

\footnotetext{
${ }^{1}$ This assumption can be justified based on the idea that the government of country- $i$ chooses how much debt to issue in order to maximize the chance of the country-i's survival (therefore the rent enjoyed by the incumbent government) in refinancing its existing debt. The maximum debt issuance becomes strictly optimal if we introduce noise in the country's fundamental repayment ability so that country- $i$ survives
} 
country rolls over its debt and does not default as long as:

$$
p_{t}^{i} B_{t+1}^{i} \geq b_{t}^{i}
$$

If the country defaults, we assume that debt holders receive zero and that the country is shut out of the debt market going forward.

\section{Analysis}

Denote $f^{i} \equiv p^{i} B_{t+1}^{i}$ as the proceeds from the country-i's bond issue at date $t$; it is also the funding that goes to country-i. There are three conditions that characterize the equilibrium:

(i) Country- $i$ does not default on its debts if

$$
f^{i} \geq b_{t}^{i}
$$

(ii) Investors pay $f$ to purchase bonds of the two countries:

$$
f^{A}+f^{B}=f
$$

(iii) If investors purchase some of the bonds of both country A and B, then the returns on these bonds must be equal by the absence of arbitrage:

$$
\frac{B_{t+1}^{B}}{f^{B}}=\frac{B_{t+1}^{A}}{f^{A}} \Rightarrow \frac{f^{B}}{f^{A}}=\frac{B_{t+1}^{B}}{B_{t+1}^{A}} .
$$

These three equilibrium conditions help us graphically illustrate our main points using a series of figures. We start with a benchmark parametrization in which joint safety of both countries arises in equilibrium. We then individually vary parameters such that that the debt issued by one country becomes the safe asset in equilibrium.

\subsection{Benchmark: Joint Safety and Equilibrium Selection}

Panel (a) of Figure 2 illustrates the equilibrium for parameters such that both countries are able to rollover their debts, and hence the debts of both countries are safe. The $\mathrm{x}$-axis is $f^{A}$, the funding going to country $\mathrm{A}$, while the $\mathrm{y}$-axis is $f^{B}$, the funding going to country B. The small-dash orange lines delineate default and no-default regions, corresponding to condition (i): the vertical (horizontal) line is for country A (B). In the upper right quadrant, each country receives sufficient funding to rollover its period- $t$ debts (by issuing $t+1$ bonds) so that both countries are safe. The grey downward sloping line corresponds to condition (ii), the aggregate budget equation stating that the $f$ of the investors equals the sum of the proceeds of each country's debt issuance. In Panel (a) of Figure 2, the aggregate budget equation crosses through the upper-right quadrant: the interval indicated by the thick black line are all points so that it is feasible to rollover both country's debts. The green upward sloping dashed-line that begins at the origin is the no-arbitrage condition (iii). We have

probalistically, as in He et al. [2015]. For simplicity, we abstract away from such noise in this paper. 
drawn this line for a special case of the model where $b_{t+1}^{i}=B_{t+1}^{i}=b_{t}^{i}$, which corresponds to a "steady-state" version of the model. In this case, the line for condition (iii) connects through the intersection of the boundaries of the no-default regions since $\frac{B_{t+1}^{B}}{B_{t+1}^{A}}=\frac{b_{t}^{B}}{b_{t}^{A}}$.

There are three potential equilibria in this case, which we have marked as E1, E2, and E3. Equilibrium E1 is where both country's debts are safe. If investors expect that others invest in both countries' debts in the right portions so that both countries are safe and returns are equalized, then point E1 is an equilibrium. However, this is not the only equilibrium. Equilibrium E2 corresponds to a case where investors expect that country B will receive no funding and default for certain. Given this belief, investors find it optimal to purchase country A's debt only. As a result, only country A receives funding, and point E2 is an equilibrium. Finally, the converse case occurs at point E3, where country A defaults and country B receives all of the funding.

We analyze the model assuming that date- $t$ investors with $f$ units of savings coordinate on the equilibrium that is welfare maximizing for these date- $t$ investors. This seemingly adhoc equilibrium selection criterion in fact shares the similar flavor as in He et al. [2015], from the perspective of welfare in the resulting equilibrium. In that paper, we use global games techniques to refine the selection of equilibria in a richer model, and provide results that are consistent with the simpler analysis in this paper (i.e. the "nowhere else to go effect"). Under this welfare-maximum selection criterion, the equilibrium (designated by a star) is at point E1. Investor welfare is highest when the amount of safe assets in the economy is highest as in this case investors receive the highest return on their investment of $f$. Thus the joint safety region corresponding to point E1 is the best equilibrium for investors.

\subsection{Safe Asset Equilibrium: Size Benefit and Negative Beta}

\section{Size benefit}

Figure 2 Panel (b) depicts the case where country A's date-t debts are sufficiently larger than the benchmark case in Panel (a) so that the joint safety possibility E1 disappears. In this case, the only equilibria that are possible are points E2 or E3. But point E2 yields higher investor welfare because country $\mathrm{A}$ has a larger float of debt than country $\mathrm{B}\left(B_{t+1}^{A}>B_{t+1}^{B}\right)$. That is, investors have more safe assets in equilibrium E2 compared to equilibrium E3. Therefore, we have a situation where a country with a large debt to rollover causes the country's bonds to be selected as the safe asset. ${ }^{2}$

We can relate the shift in equilibrium from E1 to E2 to world events. Worsening turmoil in both the US and the world in 2008 led to increased financing needs for countries. As a result, the joint safety equilibrium disappeared, and investors concentrated their safe asset demand on the largest safe debt market: US government debt (country A in the model).

Figure 2 Panel (c) presents a similar result of debt float in a different way. We break the steady state paramerization of earlier, and we suppose that country A is prospectively able to (and chooses to) issue a larger amount of safe debt. We take a case where the joint

\footnotetext{
${ }^{2}$ The large debt of country A can lead to loss of a safety of country A. This case will occur if $f$ is small, in which case there may not be enough funds to rollover country A's debts, so that both E1 and E2 become infeasible and equilibrium is at E3. For example, if the world demand for safe assets $(f)$ falls, then country A will face rollover risk. This is explored in further detail in He et al. [2015].
} 


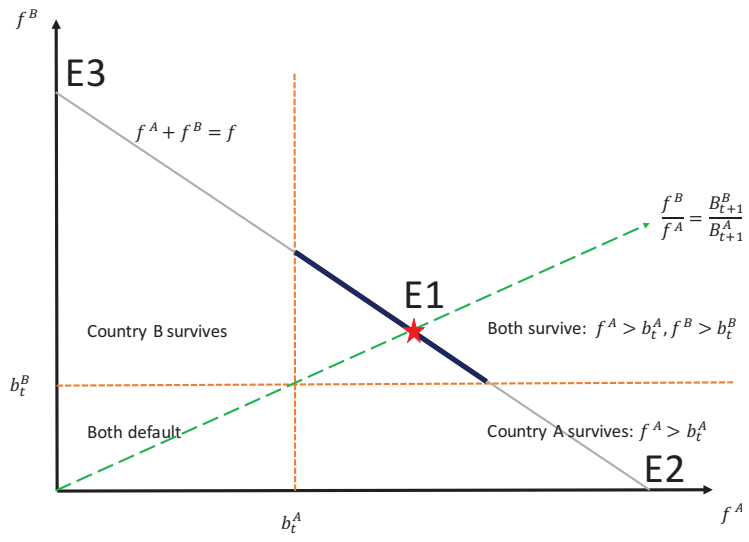

(a) Joint safety equilibrium

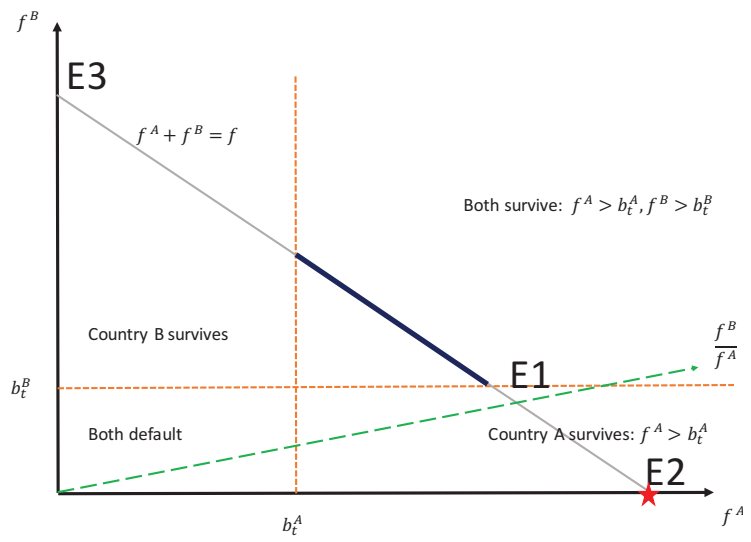

(c) Large country A is prospectively able to (and chooses to) issue a larger amount of safe debt $B_{t+1}^{A}$

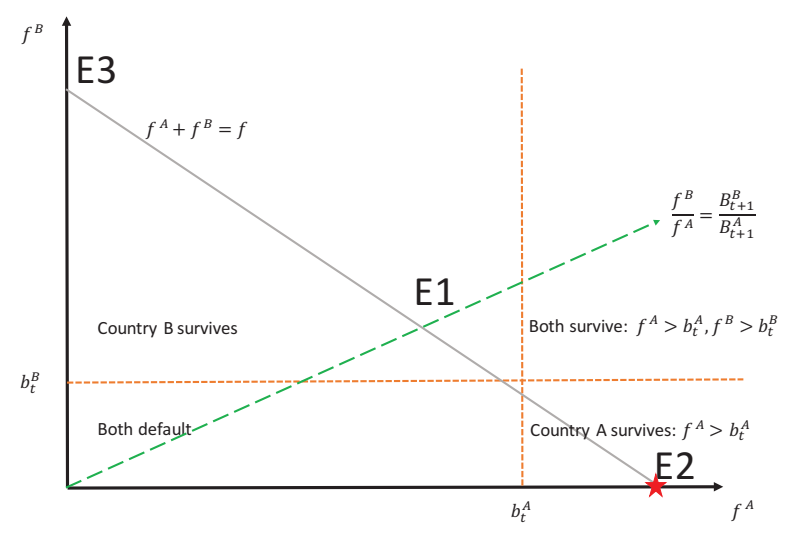

(b) Larger initial debt $b_{t}^{A}$ by large country $A$

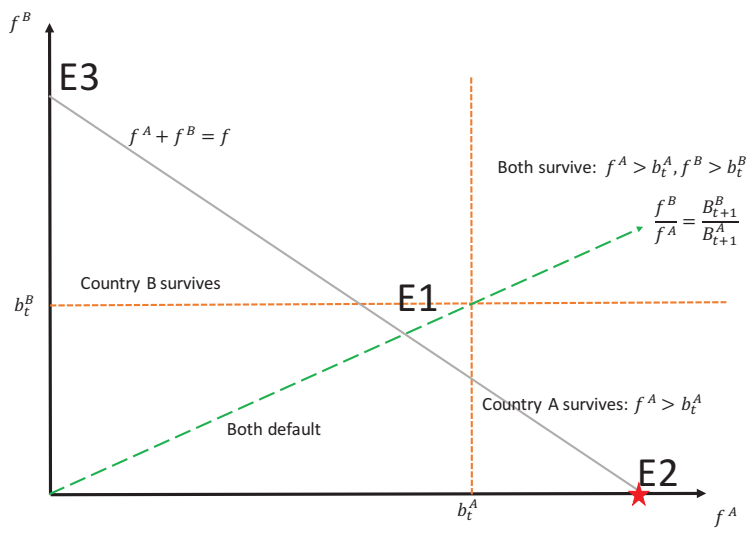

(d) Negative beta: Lower world fundamental (larger initial debts)

Figure 2: Different cases of safe asset equilibrium 
safety region is budget feasible. However, to achieve this joint safety equilibrium, country B would have to sell bonds offering a lower yield to investors than country A. The dashed green line, corresponding to condition (iii), is now flatter compared to the benchmark case in Panel (a). Since returns across the bonds must be equalized in any equilibrium by condition (iii), point E1 with joint safety cannot be an equilibrium. Given the default possibility, the only equilibrium that emerges is at point E2 where only country A debt is safe. Again, we have the result that the debt issued by the large country has an advantage in being the safe asset over the debt of the small debt country. ${ }^{3}$

These cases also point to a novel channel of contagion from the US financial crisis of 2008 to the European sovereign debt crises of 2010 and beyond. During and after the US financial crises, the supply of US safe assets rose through both the increased financing needs of the US Treasury and through the Federal Reserve's quantitative easing program whereby the government purchased mortgage-backed securities and paid with interest-bearing bank reserves. The expansion of supply in US debt can be seen as a shift from equilibrium E1 to equilibrium E2. European sovereign debt (country B) then loses its safety properties, precipitating a sovereign debt crisis. A novelty of the mechanism of our model is that the shift in equilibrum from E1 to E2 can lead to a fall in the interest on US government debt. That is, the debt crisis in Europe is not precipated by a rise in the US interest rate, but rather through a shift in safe asset status. This shift equates to a negative beta: we further develop this point next.

\section{Negative beta asset}

The movement of US Treasury yields during the 2007/09 financial crisis, as illustrated in Figure 1, highlights the negative beta of US Treasury bonds. The negative beta is one of the defining features of a safe asset: in bad times, the price of the safe asset rises (the yield falls) in a flight to quality. In our simple model, the safe asset is the debt issued by the large country A, which indeed exhibits a negative beta. To see this, consider the following thought experiment. Suppose that the countries in our model also receive some fiscal surplus $\theta^{i}=\theta B_{t+1}^{i}$ at date 1 , which can be used to repay the existing debt $b_{t}^{i}$ due today. Here, a negative $\theta$ represents a deficit. This modification only affects the default condition (i), which now becomes

$$
\theta B_{t+1}^{i}+f^{i} \leq b_{t}^{i}
$$

Now consider a negative shock to $\theta$ which corresponds to bad times. Relative to the benchmark case in Figure 2, Panel (a), this negative fundamental shock shifts the two vertical and horizontal lines outward (proportionately), as indicated by Panel (d) in Figure 2. There, the joint safety equilibrium in point E1 fails to survive given a sufficiently negative shock to $\theta$. Instead, the resulting equilibrium moves to point E2, in which investors only buy country A bonds. To summarize, following a negative fundamental shock our model predicts a rise in the price of country A's debt, implying that the debt of country A has a negative beta.

\footnotetext{
${ }^{3}$ There is a symmetric case where the dashed green line crosses the budget equation in the upper left quadrant. This case, which corresponds to one where $B_{t+1}^{B}>B_{t+1}^{A}$ will lead investors to choose country B as the safe asset, given that country $\mathrm{B}$ offers the maximum safety to investors.
} 


\section{Conclusion}

The safety of a safe asset depends on investor beliefs. Safety is endogenous, and when investors believe an asset will be safe, their actions can make that asset safe. Our simple model highlights the "nowhere else to go" aspect of safety, and illustrates the benefit of a large debt size. Other considerations such as the ability of a sovereign to service its debt, as measured for example by its fiscal surplus, will also be important in a full-blown model. We analyze this case in He et al. [2015], and uncover another interesting result. The safety of an asset does not depend on the absolute fiscal surplus of a country, but the country's fiscal surplus relative to other countries' fiscal surplus. That is, even if the US fiscal position deteriorates, US government debt will remain a safe asset as long as the US fiscal position remains superior to other countries. ${ }^{4}$

Our perspective on asset safety emphasizes coordination, as opposed to (exclusively) the income process backing the asset, as in conventional analyses of credit risk. In the world, the assets that investors own as their safe assets are largely government debt, money and bank debt. For these assets, valuation has a significant coordination component as in our model, underscoring the relevance of our perspective.

\section{References}

Ricardo J Caballero and Arvind Krishnamurthy. Global Imbalances and Financial Fragility. American Economic Review, 99(2):584-588, 2009. URL http: //www . jstor .org/stable/25592462.

Ricardo J Caballero, Emmanuel Farhi, and Pierre-Olivier Gourinchas. An Equilibrium Model of "Global Imbalances" and Low Interest Rates. American Economic Review, 98(1):358393, 2008. URL http://www.jstor.org/stable/29729975.

Zhiguo He, Arvind Krishnamurthy, and Konstantin Milbradt. A model of safe asset determination. Working Paper, 2015.

Arvind Krishnamurthy and Annette Vissing-Jorgensen. The Aggregate Demand for Treasury Debt. Journal of Political Economy, 120(2):233-267, 2012. URL http://www . jstor .org/stable/10.1086/666526.

\footnotetext{
${ }^{4}$ Additionally, while in our model all of the safe assets in which investors invest have the coordination element, it is straightforward to extend the model to consider a case with some fully collateralized safe assets. As we discuss in, He et al. [2015] as long as there are not too many of these assets, the coordination aspect of our model continue to be relevant.
} 